\title{
Human Monoclonal Antibody-Drug Conjugates in the Experimental Treatment of Malignant Gliomas
}

\author{
-Studies In Vitro and In Vivo-
}

\author{
Jianhong ZHU, Hiroshi TAKAHASHI, and Shozo NAKAZAWA
}

Department of Neurosurgery, Nippon Medical School, Tokyo

\begin{abstract}
The chemotherapeutic agents doxorubicin (DXR) and 4'-epi-doxorubicin were separately conjugated to the human monoclonal antibody CLNIgG, which binds strongly to human malignant glioma cells. The antibody-drug conjugates were more potent than the free drugs in killing human glioma cells in vitro and in vivo (subcutaneous glioma model). A biodistribution study using $\left[14-{ }^{14} \mathrm{C}\right] \mathrm{DXR}-\mathrm{CLNIgG}$ conjugate indicated that immunoconjugates delivered at least five times more DXR to glioma tissues than free DXR alone in nude mice without increasing the concentration in other tissues. In a nude rat intracerebral glioma model, intracarotid hyperosmolar perfusion to achieve blood-brain barrier (BBB) opening caused a $640 \%$ increase in the DXR-CLNIgG concentration in intracerebral tumor tissue. Human monoclonal antibody-drug conjugates in combination with BBB opening is a potential new approach to the treatment of malignant gliomas.
\end{abstract}

Key words: human monoclonal antibody, glioma, doxorubicin, 4'-epi-doxorubicin, conjugate, blood-brain barrier

\section{Introduction}

Malignant gliomas are the most common of all primary brain tumors, and are also among the most difficult to treat. Advances in the conventional treatment of malignant gliomas, including surgery, ${ }^{10}$ ) radiation therapy, and systemic chemotherapy, have not essentially improved the prognosis of this disease for the past 20 years. ${ }^{12,16)}$ The 2 -year survival rate for glioblastoma multiforme is still less than $20 \%{ }^{6,211}$ A new therapy must therefore be developed.

Monoclonal antibody technology can provide reagents that selectively recognize cell surface antigens expressed by neoplastic tissues. However, in the area of immunotherapy, monoclonal antibodies are just beginning to fulfill the potential inherent in their great specificity for recognizing and selectively binding to antigens on tumor cells. The initial results of murine monoclonal antibodies in glioma therapy have been much less satisfactory, possibly due to the

Received June 28, 1993; Accepted December 30, 1993 immunogenicity of murine monoclonal antibodies, limitations to the efficacy of unmodified antibodies, and inadequate delivery or penetration across the blood-brain barrier (BBB) ${ }^{6,19)}$

Although murine monoclonal antibodies are of value in the therapy of human diseases, their effectiveness is limited because rodent monoclonal antibodies, being xenogenic agents, are immunogenic and elicit a human immune response that neutralizes their therapeutic effect. ${ }^{(9)}$ One solution to the problem of immunogenicity is to use human monoclonal antibodies. CLNIgG was produced by a human $x$ human hybridoma, CLNH11, which was derived from uterine lymph node cells from a case of human uterine cancer. ${ }^{5}$ CLNIgG was shown to react with human malignant gliomas as well as autologous cervical carcinomas, ${ }^{\prime \prime}$ but reacted with neither normal adult and fetal brain tissues nor other, non-neural, tissues. $^{8 \text { ) }}$

The limited efficacy of many unmodified monoclonal antibodies has led to an alternative approach, using these agents as carriers of cytotoxic substances. ${ }^{2,17)}$ More than 30 years ago, the use of chemotherapy to treat malignant brain tumors was 
introduced as a supplement to surgery and radiation. ${ }^{20)}$ Experience has shown that systemic chemotherapy is not a cure for such tumors, because the lack of specificity for malignant cells leads to doselimiting side effects and unacceptable toxicity. A promising area of investigation is the targeting of a cytotoxic agent to the tumor cells, which could be achieved by the preparation of antibody-drug conjugates.

Here we report an experimental study in the mouse using human monoclonal antibody conjugated with cytotoxic agents and osmotic opening of the BBB for antibody delivery into brain tumors.

\section{Materials and Methods}

\section{Cell lines}

Human malignant glioma (astrocytoma grade III and IV) cell lines, U373-MG and U87-MG, were described previously. ${ }^{15,18)}$ The U373-MG cells were grown in Eagle's minimum essential medium supplemented with $10 \%$ fetal calf serum (FCS). The U87-MG cells were maintained in L-15 medium containing 10\% FCS.

\section{Monoclonal antibody and chemotherapeutic agent}

The human monoclonal antibody CLNIgG, derived from human uterus cancer lymph node cells, ${ }^{5 /}$ is found to bind strongly to human malignant glioma cells. ${ }^{18)}$ CLNIgG was provided by the Hagiwara Institute of Health (Kasai, Hyogo). The antigen recognized by CLNIgG is a membrane protein (226 kd) expressed by human malignant glioma cells." Doxorubicin (DXR) and 4'-epi-doxorubicin (epiDXR, a less cardiotoxic analogue of $\mathrm{DXR}^{7 /}$ ) were donated by Farmitalia Carlo Erba (Milano, Italy). The chemical structures are shown in Fig. 1.

\section{Preparation of immunoconjugates}

DXR or epi-DXR was conjugated to CLNIgG through a dextran bridge as previously described. ${ }^{21}$ Briefly, dextran- $T_{40}$ was oxidized with sodium periodate and incubated with DXR or epi-DXR for 20 hours at $4^{\circ} \mathrm{C}$. The CLNIgG was then added and the mixture was left for a further 48 hours. The antibody-drug conjugates were separated from the unbound drug with a Sephadex G-100 (Pharmacia, Uppsala, Sweden) gel filtration apparatus. Protein analysis and spectroscopic analysis $\left(\mathrm{OD}_{495 \mathrm{~nm}}\right)$ showed that 38 molecules of the drug bound to one molecule of antibody. Normal human IgG (nIgG)drug conjugate was prepared as a control in a similar way.

IV. Subcutaneous and intracerebral tumor models

The subcutaneous glioma model used 6-week-old male BALB/c athymic mice (nu/nu) inoculated subcutaneously in the back with $5 \times 10^{6}$ U87-MG glioma cells via a 26-gauge needle. ${ }^{4}$ The intracerebral glioma model used male Fischer $344 / \mathrm{Jcl}$ nude rats (run/run) (Clea Japan Inc., Tokyo) weighing 80-90 $\mathrm{g}$ which were injected with $25 \mu \mathrm{l}$ of U87-MG glioma cell suspension $\left(5 \times 10^{5}\right.$ cells $)$ into the right hemisphere at a depth of $2.5 \mathrm{~mm}$. The intracerebral tumors were identified on the 9th day after inoculation by magnetic resonance (MR) imaging with a JNM-IM60 imaging system (6.3 T; JEOL, Tokyo).

\section{Pharmacological activities of immunocon- jugates in vitro}

The immunoreactivity was measured before and after drug conjugation by determining the binding to glioma cells with an enzyme-linked immunosorbent assay (ELISA). The cytotoxic activity of the antibody-drug conjugates was assessed by a ${ }^{3} \mathrm{H}$ thymidine incorporation assay. Briefly, $5 \times 10^{5}$
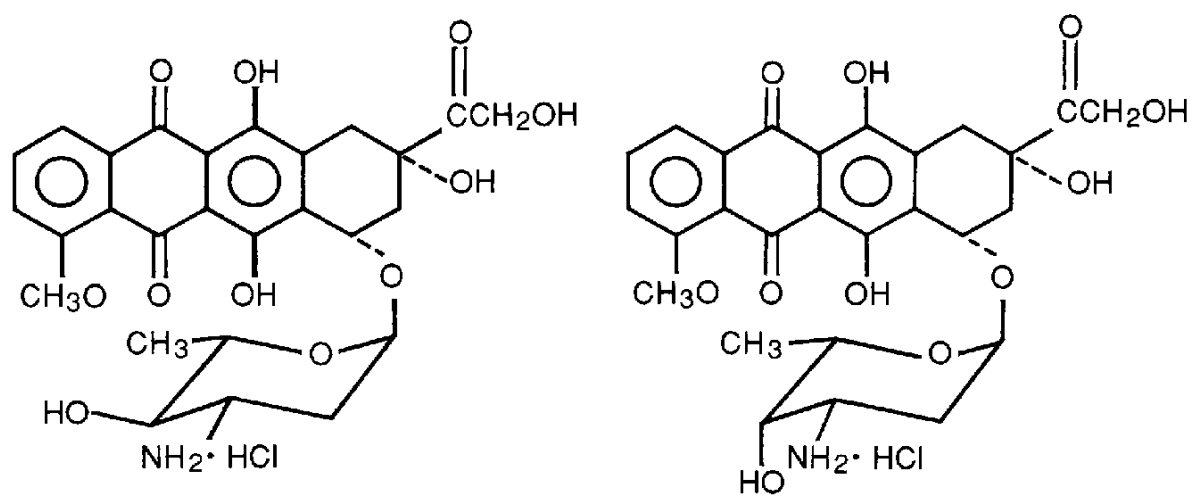

Fig. 1 Chemical structures of epi-DXR (left) and DXR (right). 
U373-MG cells/well were exposed to the serially diluted immunoconjugates for 4 hours at $37^{\circ} \mathrm{C}$. The cells were then washed twice. Subsequently, $1 \mu \mathrm{Ci}$ of ${ }^{3} \mathrm{H}$-thymidine (Amersham, Buckinghamshire, U.K.) was added to each well followed by incubation for 18 hours. The cells were harvested, and the incorporation of ${ }^{3} \mathrm{H}$-thymidine was determined with a $\beta$ counter (Aloka, Tokyo).

\section{Efficacy of immunoconjugates in vivo}

Seven days after tumor inoculation, the nude mice that had developed a palpable subcutaneous tumor were selected for treatment with intraperitoneal injection of one of the following: a) phosphate-buffered saline (PBS), b) epi-DXR-CLNIgG conjugate, or c) epi-DXR alone at 3-day intervals for a total of four times. Each treatment group contained six mice. Each animal received a total equivalent dose of 1 $\mathrm{mg} / \mathrm{kg}$ of epi-DXR or $8 \mathrm{mg} / \mathrm{kg}$ of CLNIgG, or both. Tumor growth was determined every 3 rd day by measuring the short (a) and long (b) dimensions of the tumors with calipers. The tumor volumes were calculated by the following formula:

tumor volume $=\left(a^{2} \cdot b\right) / 2$

The differences in tumor volumes between experimental groups were analyzed by Wilcoxon's rank test. ${ }^{31} \mathrm{P}-\mathrm{MR}$ spectra were examined in vivo to measure the energy metabolism of tumors using a JSM-SMR 270 spectrometer system (JEOL). Twelve hours after the first treatment, the subject animals were anesthetized by nembutal and fixed in the MR apparatus so that the tumor mass was located on a four-turn surface coil of $1.0 \mathrm{~cm}$ in diameter, providing a resonant signal of ${ }^{31} \mathrm{P}$ from the tumor.

\section{Biodistribution of immunoconjugates}

The tissue distributions of DXR-CLNIgG conjugates and of DXR after intraperitoneal injection were compared in nude mice bearing U87-MG tumors. Briefly, $1 \mu \mathrm{Ci}$ of $\left[14^{14} \mathrm{C}\right] \mathrm{DXR}$ (Amersham) or $2 \mu \mathrm{Ci}$ of $\left[14-{ }^{14} \mathrm{C}\right] \mathrm{DXR}-\mathrm{CLNIgG}$ was injected intraperitoneally into seven mice with an average tumor weight of $400 \mathrm{mg}$. Twenty-four hours after the injection, the mice were sacrificed under nembutal anesthesia. Major tissues were dissected, weighed, and dissolved in $4 \mathrm{ml}$ of Soluene 350 (Packard, Meriden, Conn., U.S.A.). The dissolved tissues were then counted on a $\beta$-counter using Hionic-Fluor (Packard) as the liquid scintillation cocktail. The results were expressed as a percentage of the injected dose per gram of tissue ( $\% \mathrm{ID} / \mathrm{g})$.

\section{Osmotic BBB opening}

The delivery of DXR-CLNIgG conjugates to intracerebral tumors after BBB opening was evaluated in $F_{344}$ nude rats bearing human glioma xenografts 10 days after tumor inoculation. The technique of BBB disruption in rats was according to Neuwelt et al. ${ }^{13)}$ All rats underwent right carotid artery exposure and were infused via a carotid artery catheter with physiological saline in control studies or with $20 \%$ mannitol $(1 \mathrm{mg} / \mathrm{kg})$ in $\mathrm{BBB}$ opening studies. $2 \mu \mathrm{Ci}$ of $\left[14-{ }^{14} \mathrm{C}\right] \mathrm{DXR}-\mathrm{CLNIgG}$ was administered via the same catheter immediately after saline or mannitol infusion over 1 minute. Thirty minutes after conjugate administration, the animals were sacrificed under nembutal anesthesia and the tumor and 1-2 $\mathrm{mm}$ of brain tissue immediately surrounding the tumor, the contralateral hemisphere of the brain, and other organs and tissues were dissected for [14 $\left.{ }^{14} \mathrm{C}\right]$ DXR-CLNIgG determination as described above.

\section{Results}

\section{Pharmacological activities of immunoconjugates in vitro}

CLNIgG conjugated with 38 molecules of epiDXR or DXR retained about $90 \%$ of its immunoreactivity after conjugation measured by ELISA. The cytotoxic activity of the immunoconjugates was monitored by an assay measuring ${ }^{3} \mathrm{H}$-thymidine incorporation, since epi-DXR and DXR are known to intercalate with deoxyribonucleic acid and cause cell cycle arrest in the $G_{2}$ phase. The epi-DXR-CLNIgG

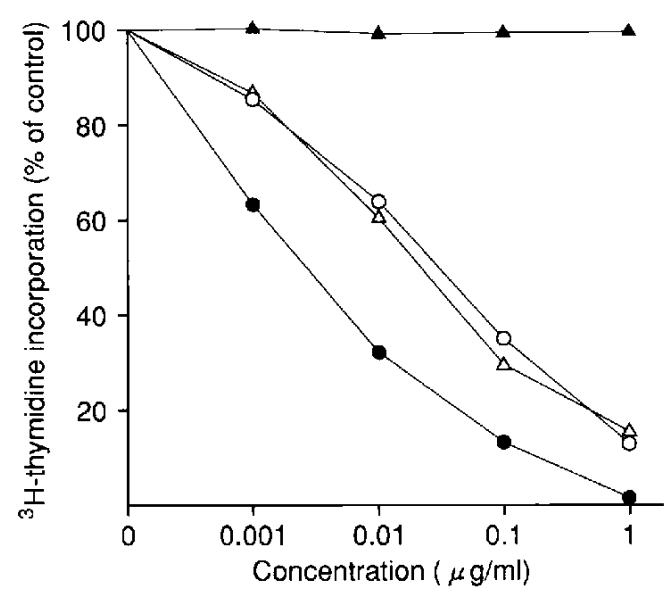

Fig. 2 Cytotoxicity of epi-DXR-CLNIgG conjugate $(\bullet)$, epi-DXR (O), CLNIgG (४), and CLNIgG with epi-DXR $(\triangle)$. The values are the means of triplicate assessments. 


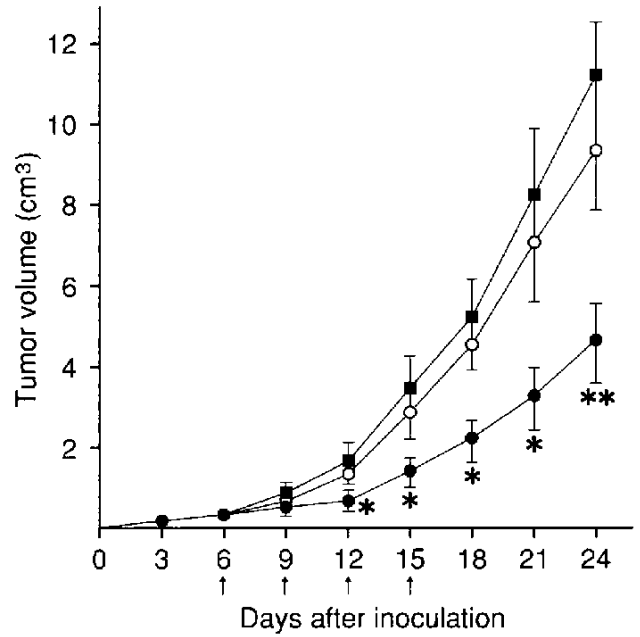

Fig. 3 Growth curves of human glioma xenografts in nude mice after drug treatments (arrows) with PBS ( $\square)$, epi-DXR $(0)$, and epi-DXRCLNIgG $(\bullet)$. Bars indicate \pm SE of the mean. ${ }^{*} \mathrm{p}<0.01$ vs. PBS control group, ${ }^{* *} \mathrm{p}<0.001$ $v s$. epi-DXR group.
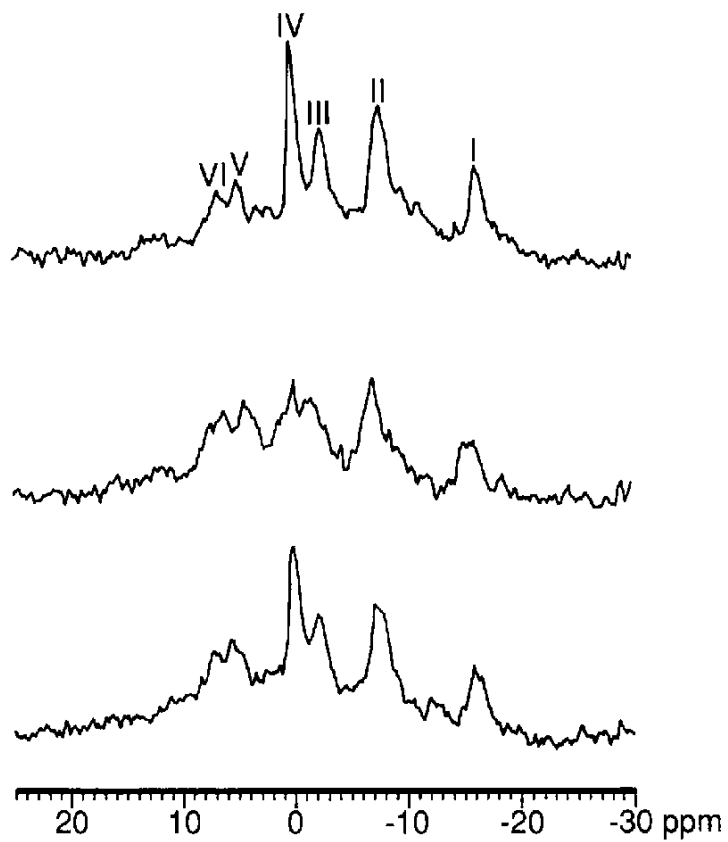

Fig. $4{ }^{31}$ P-MR spectra of gliomas in three mouse groups treated with PBS (upper), epi-DXRCLNIgG (middle), and epi-DXR (lower). I: $\beta$-ATP, II: $\alpha$-ATP and $\alpha$-ADP, III: $\gamma$-ATP and $\beta$-ADP, IV: phosphocreatine, $\mathrm{V}$ : inorganic phosphate, VI: phosphomonoesters. conjugate was found to be 11 times more potent than free epi-DXR in killing U373-MG glioma cells (Fig. 2 ). The $50 \%$ inhibitory concentration $\left(\mathrm{IC}_{50}\right)$ of epiDXR-CLNIgG was $4.1 \times 10^{-9} \mathrm{M}$, while that of free epi-DXR was $4.4 \times 10^{-8} \mathrm{M}$. A mixture of CLNIgG antibody and epi-DXR did not demonstrate a significantly increased cytotoxic efficacy $\left(\mathrm{IC}_{50} 4.1 \times\right.$ $\left.10^{-8} \mathrm{M}\right)$. Epi-DXR-nIgG $\left(\mathrm{IC}_{50} 5.0 \times 10^{-8} \mathrm{M}\right)$ and epi-DXR-dextran (IC $50.4 \times 10^{-8} \mathrm{M}$ ) conjugates did not achieve greater inhibition of glioma cell growth than epi-DXR.

\section{Efficacy of immunoconjugates in vivo}

Figure 3 shows the efficacy of the various agents in suppressing tumor growth. Epi-DXR-CLNIgG clearly achieved the most favorable antitumor effects. A significant tumor growth difference $(\mathrm{p}<0.01)$ between the epi-DXR-CLNIgG and PBS control groups was observed as early as 6 days after the start of treatment. Free epi-DXR achieved only nonsignificant inhibition of tumor growth. Epi-DXRCLNIgG showed significant $(\mathrm{p}<0.001)$ inhibition of tumor growth at a treatment/control volume (T/ C) of 0.42 , as compared with a $\mathrm{T} / \mathrm{C}$ of 0.85 in the epi-DXR group, at the end of the study (day 24). The ${ }^{31}$ P-MR spectra of the tumors are shown in Fig. 4. Several peaks appear in these spectra, in descending order of resonance frequency: $\beta$-adenosine triphosphate (ATP), $\alpha$-ATP and $\alpha$-adenosine diphosphate (ADP), $\gamma$-ATP and $\beta$-ADP, phosphocreatine, inorganic phosphate, and phosphomonoesters. After treatment with epi-DXR-CLNIgG, the intensity of the ATP peaks had decreased markedly, but no such change occurred in the epi-DXR group.

\section{Biodistribution of immunoconjugates}

The most striking finding was the greater deposition of DXR in the tumor tissues by DXR-CLNIgG conjugates compared to the free drug (Table 1). Only $0.77 \%$ of the total $\left[14-{ }^{14} \mathrm{C}\right] \mathrm{DXR}$ injected was present in each gram of tumor tissue, whereas $3.9 \%$ of the total $\left[14-{ }^{14} \mathrm{C}\right] \mathrm{DXR}-\mathrm{CLNIgG}$ injected was present in each gram of tumor. Thus the immunoconjugates achieved a delivery of five times as much DXR to the target site. Another notable point was that tumor' tissue ratios of $\left[14-{ }^{14} \mathrm{C}\right] \mathrm{DXR}-\mathrm{CLNIgG}$ were nine times those of $\left[14-{ }^{14} \mathrm{C}\right] \mathrm{DXR}$ in the bone marrow, eight times in the intestines, and seven times in the heart.

\section{Osmotic BBB opening}

Following intracarotid perfusion with mannitol, there was a $640 \%$ increase in the delivery of $\left[14-{ }^{14} \mathrm{C}\right]$ DXR-CLNIgG into the intracerebral glioma tissues 
Table 1 Distribution of $\left[14-{ }^{-14} \mathrm{C}\right] \mathrm{DXR}-\mathrm{CLNIgG}$ in human glioma-grafted nude mice

\begin{tabular}{|c|c|c|c|c|}
\hline \multirow{2}{*}{ Tissue } & \multicolumn{2}{|c|}{ Specific tissue activity $(\% \mathrm{ID} / \mathrm{g})$} & \multicolumn{2}{|c|}{$\begin{array}{l}\text { Tumor } / \text { tissue ratio of radioactivity } \\
(\mathrm{cpm} / \mathrm{g} \text { tumor } / \mathrm{cpm} / \mathrm{g} \text { tissue })\end{array}$} \\
\hline & {$\left[14-{ }^{14} \mathrm{C}\right] \mathrm{DXR}-\mathrm{CLNIgG}$} & {$\left[14^{-14} \mathrm{C}\right] \mathrm{DXR}$} & {$\left[14-{ }^{14} \mathrm{C}\right] D X R-C L N I g G$} & {$\left[14^{-14} \mathrm{C}\right] \mathrm{DXR}$} \\
\hline Tumor & $3.904 \pm 0.663$ & $0.772 \pm 0.044$ & 1.0 & 1.0 \\
\hline Blood & $1.350 \pm 0.333$ & $0.694 \pm 0.083$ & $2.935 \pm 0.265$ & $1.118 \pm 0.075$ \\
\hline Stomach & $1.039 \pm 0.052$ & $1.078 \pm 0.321$ & $3.752 \pm 0.583$ & $0.776 \pm 0.303$ \\
\hline Liver & $1.517 \pm 0.116$ & $1.379 \pm 0.102$ & $2.563 \pm 0.290$ & $0.562 \pm 0.071$ \\
\hline Spleen & $2.782 \pm 1.180$ & $2.882 \pm 0.515$ & $1.617 \pm 0.472$ & $0.274 \pm 0.058$ \\
\hline Pancreas & $0.843 \pm 0.208$ & $2.202 \pm 0.772$ & $4.823 \pm 1.247$ & $0.397 \pm 0.128$ \\
\hline Kidney & $2.355 \pm 0.529$ & $3.175 \pm 0.411$ & $1.694 \pm 0.207$ & $0.243 \pm 0.044$ \\
\hline Small intestine & $1.030 \pm 0.210$ & $1.774 \pm 0.386$ & $3.835 \pm 0.525$ & $0.450 \pm 0.114$ \\
\hline Large intestine & $1.095 \pm 0.667$ & $2.013 \pm 0.086$ & $3.405 \pm 1.274$ & $0.384 \pm 0.037$ \\
\hline Heart & $0.445 \pm 0.156$ & $0.736 \pm 0.352$ & $9.374 \pm 2.893$ & $1.272 \pm 0.722$ \\
\hline Lung & $1.117 \pm 0.439$ & $1.278 \pm 0.565$ & $4.013 \pm 1.998$ & $0.676 \pm 0.261$ \\
\hline Bladder & $1.407 \pm 0.234$ & $2.629 \pm 0.170$ & $2.791 \pm 0.363$ & $0.294 \pm 0.008$ \\
\hline Muscle & $0.512 \pm 0.052$ & $0.584 \pm 0.140$ & $7.649 \pm 1.281$ & $1.561 \pm 0.450$ \\
\hline Bone marrow & $0.602 \pm 0.103$ & $1.455 \pm 0.276$ & $5.387 \pm 1.534$ & $0.545 \pm 0.122$ \\
\hline
\end{tabular}

Values are mean \pm SE of three to four mice at 24 hours after injection of $\left[14-{ }^{14} \mathrm{C}\right] \mathrm{DXR}-\mathrm{CLNIgG}$ or $\left[14-{ }^{14} \mathrm{C}\right] \mathrm{DXR}$.

Table $2 \quad\left[14-{ }^{14} \mathrm{C}\right] \mathrm{DXR}-\mathrm{CLNIgG}$ concentration in nude rats after $\mathrm{BBB}$ opening

\begin{tabular}{lcc}
\hline \multirow{2}{*}{ Tissue } & \multicolumn{2}{c}{$\left[14-{ }^{14} \mathrm{C}\right] \mathrm{D} X \mathrm{R}-\mathrm{CLNIgG}(\% \mathrm{ID} / \mathrm{g})$} \\
\cline { 2 - 3 } & BBB opening $(+)$ BBB opening (-) \\
\hline Brain tumor & 6.320 & 0.982 \\
Brain around tumor & 3.841 & 0.065 \\
Brain contralateral & 0.177 & 0.010 \\
$\quad$ to tumor & 0.924 & 0.902 \\
Stomach & 1.180 & 1.246 \\
Spleen & 1.809 & 1.855 \\
Liver & 1.223 & 1.143 \\
Kidney & 1.049 & 0.931 \\
Intestine & 0.573 & 0.648 \\
Heart & 0.865 & 1.004 \\
Lung & 0.746 & 0.786 \\
Bone marrow & &...
\end{tabular}

(Table 2). BBB opening also increased the delivery of immunoconjugates to the brain around the tumor and to the contralateral brain tissues. The highest concentration of immunoconjugates was in the tumor tissues. The distribution of immunoconjugates in non-neural tissues showed no difference between the BBB opening and physiological saline control groups.

\section{Discussion}

We prepared immunoconjugates by coupling CLNIgG to DXR or epi-DXR through a dextran bridge. The cell surface binding of the resultant antibody-drug conjugates to human glioma cells was very efficient, and was similar to that of the original antibody. Epi-DXR-CLNIgG was 11 times more potent than free epi-DXR against glioma cells. Since free CLNIgG in the absence of lymphocytes or of complement cannot exert direct cytotoxicity against glioma cells (Fig. 2), and since it lacks synergy with epi-DXR, we interpret the present finding of increased cytotoxicity of epi-DXR when conjugated to CLNIgG as an indication that the antibodies have directed the drug to the glioma cells. Alternatively, epi-DXR conjugated through a dextran bridge to protein may have caused a non-specific uptake by tumor cells. However, this was not substantiated in our experiments in which non-specific epi-DXRnIgG and epi-DXR-dextran conjugates achieved no better cytotoxicity than free epi-DXR. Thus, our results indicate that the cytotoxic activity of our immunoconjugates was mediated by the specificity of the CLNIgG antibody.

The results of treatment with immunoconjugates in vivo demonstrate that epi-DXR-CLNIgG is very effective in suppressing the growth of established human glioma xenografts in nude mice ( $\mathrm{T} / \mathrm{C} 0.42)$. This improvement was significantly $(\mathrm{p}<0.001)$ better than that resulting from treatment with epi-DXR (T/C 0.85). ${ }^{31} \mathrm{P}-\mathrm{MR}$ spectrum studies further showed that ATP peaks decreased after treatment with epiDXR-CLNIgG, indicating that the energy metabolism and cell growth of the tumors were inhibited. ${ }^{9)}$

Our biodistribution study provided further 
evidence that the DXR-CLNIgG conjugate can deliver at least five times more DXR $(3.9 \% \mathrm{ID} / \mathrm{g})$ to the tumor tissue than the free form $(0.77 \% \mathrm{ID} / \mathrm{g})$. Moreover, less DXR-CLNIgG than DXR accumulated in the bone marrow and heart tissues, indicating that antibody-drug conjugates effectively increase the therapeutic index of cytotoxic agents. These results are consistent with the tumor suppression observed in vivo.

A major potential difficulty with immunoconjugate therapy is the large size of the molecules which limits the transvascular diffusion into brain tumor tissue through the BBB. ${ }^{6}$ Transient hyperosmolar disruption of the BBB has been performed safely in animals and in man, generally in studies involving the delivery of chemotherapeutic agents to the central nervous system. ${ }^{11)}$ Some evidence exists that this technique can also be used to deliver large molecules such as antibodies. ${ }^{13)}$ In the present study, we evaluated the delivery of antibody-drug conjugates into brain tumors and the immediately adjacent brain tissues after osmotic disruption of the BBB in nude rats. Our findings demonstrate several points. The delivery of DXR-CLNIgG conjugates into intracerebral tumors is increased by $640 \%$ after transient $\mathrm{BBB}$ opening with the hyperosmolar agent mannitol administered by the intracarotid route. After $\mathrm{BBB}$ opening, the immunoconjugate concentration in the cerebral tissues around the tumor was also increased. The intracerebral tumor tissue, however, contained more immunoconjugates than the immediately surrounding tissues. The ipsilateral nature of $\mathrm{BBB}$ opening has been stressed by some authors. ${ }^{12)}$ In our study, increased delivery of DXR-CLNIgG occurred in bilateral hemispheres of the brain following BBB disruption, although it was much higher in the ipsilateral hemisphere. Bullard et $a l^{3)}$ found similar findings in delivering monoclonal antibodies to the normal rat brain after BBB opening. Indeed, variability in distribution based on the circle of Willis appears to be the rule rather than the exception. Since there are few receptors for the $\mathrm{Fc}$ portion of immunoglobulins in the brain, ${ }^{14)}$ the presence of immunoconjugates in the brain tissue may be the result of nonspecific binding to the $\mathrm{Fc}$ receptors on the brain cell membranes. Studies are in progress to utilize Fab fragments to reduce this effect.

Although our results show that further investigations are required for clinical trials, the present studies indicate that the use of human monoclonal antibody-drug conjugates in combination with BBB opening is a promising therapeutic strategy which optimizes the use of these novel agents for the treatment of malignant gliomas.

\section{Acknowledgments}

The authors wish to thank Miss Chizuko Ohue and Miss Sachiko Mashimo for technical assistance.

\section{References}

1) Aotsuka $Y$, Hagiwara $\mathrm{H}$ : Identification of a malignant cell-associated antigen recognized by a human monoclonal antibody. Eur $J$ Cancer Clin Oncol 24: 829-838, 1988

2) Bullard DE, Bigner DD: Applications of monoclonal antibodies in the diagnosis and treatment of primary brain tumors. J Neurosurg 63: 2-16, 1985

3) Bullard DE, Bourdon M, Bigner DD: Comparison of various methods for delivering radiolabeled monoclonal antibody to normal rat brain. $J$ Neurosurg 61: 901-911, 1984

4) Colston MJ, Fieldsteel AH, Dawson PJ: Growth and regression of human tumor cell lines in congenitally athymic (run/run) rats. $J N C I 66: 843-847,1981$

5) Hagiwara H, Sato HG: Human $x$ human hybridoma produced monoclonal antibody against autologous cervical carcinoma. Mol Biol Med 1: 245-252, 1983

6) Hall WA, Fodstad Ø: Immunotoxins and central nervous system neoplasia. J Neurosurg 76: 1-12, 1992

7) Hurteloup P: A prospective randomized phase III trial comparing combination chemotherapy with cyclophosphamide, fluorouracil, and either doxorubicin or epirubicin. J Clin Oncol 6: 679-688, 1988

8) Kokunai $T$, Tamaki $N$, Matsumoto $S$ : Antigen related to cell proliferation in malignant gliomas recognized by a human monoclonal antibody. $J$ Neurosurg 73: 901-908, 1990

9) Naruse S, Hirakawa K, Horikawa Y, Tanaka C: Measurement of in vivo ${ }^{31} \mathrm{P}$ nuclear magnetic resonance spectra in neuroectodermal tumors for the evaluation of the effects of chemotherapy. Cancer Res 45: 2429-2433, 1985

10) Nazzaro JM, Neuwelt EA: The role of surgery in the management of supratentorial intermediate and highgrade astrocytomas in adults. $J$ Neurosurg 73 : 331344,1990

11) Neuwelt EA, Barranger JA, Brady RO: Delivery of hexosaminidase $A$ to the cerebrum after osmotic modification of the blood brain barrier. Proc Natl Acad Sci USA 78: 5838-5841, 1981

12) Neuwelt EA, Bulaban E, Diehl J, Hill S, Frenkel E: Successful treatment of primary central nervous system lymphomas with chemotherapy after osmotic blood-brain barrier opening. Neurosurgery 12: 662671,1983

13) Neuwelt EA, Minna J, Frenkel E, Barnett H, McCormic CI: Osmotic blood brain barrier opening to IgM monoclonal antibody in the rat. Am $J$ Physiol 250: 875-883, 1986

14) Phillips JP, Ereman O, Anderson JR: Lym- 
phoreticular cells in human brain tumors and in normal brain. Br J Cancer 45: 61-69, 1982

15) Ponten J, Macintyre EH: Long term culture of normal and neoplastic human glia. Acta Pathol Microbiol Scand 74: 465-486, 1968

16) Salcman M: The morbidity and mortality of brain tumors. A perspective on recent advances in therapy. Neurol Clin 3: 229-257, 1985

17) Stavrou D: Monoclonal antibodies in neuro-oncology. Neurosurg Rev 13: 7-9, 1990

18) Takahashi H, Nakazawa S: Effects of a human monoclonal antibody and cytokines on human malignant glioma cells, in Tabuchi $\mathrm{K}(e d)$ : Biological Aspects of Brain Tumors. Tokyo, Springer-Verlag, 1991, pp 464-468

19) Waldmann TA: Monoclonal antibodies in diagnosis and therapy. Science 252: 1657-1662, 1991

20) Walker MD, Green SB, Byar DP: Randomized comparisons of radiotherapy and nitrosourea for the treatment of malignant glioma after surgery. $N$ Engl $J$ Med 303: 1323-1329, 1980

21) Zhu J, Du Z, Huang Q, Yang W, Wang Y: The use of anti-human glioma monoclonal antibodies for targeting chemotherapy of brain gliomas. Chin $J$ Cancer Res 2: 12-18, 1990

Address reprint requests to: H. Takahashi, M.D., Department of Neurosurgery, Nippon Medical School, 1-15 Sendagi, Bunkyo-ku, Tokyo 113, Japan. 